\title{
Para o mercado ou para a cidadania? a educação ambiental nas instituições públicas de ensino superior no Brasil
}

VANESSA MARCONDES DE SOUZA

Universidade Federal do Rio de Janeiro, Rio de Janeiro, RJ, Brasil

RESUMO

As instituições de ensino superior (IES) vêm sendo chamadas para buscar soluções para a crise ambiental. Entretanto, as diferentes visões sobre o meio ambiente podem retardar ações que levem a reais mudanças. As ações ambientais realizadas dentro das IES são consideradas ainda pontuais e pouco expressivas, sendo a visão naturalista e a crença no tecnicismo predominantes. A inserção das empresas dentro dos cursos ambientais pode influenciar a produção do conhecimento e reduzir a formação universitária ao atendimento aos interesses do mercado, retardando a superação dos problemas ambientais, uma vez que críticas sobre o atual modelo de exploração/ produção/consumo/lucro da sociedade não são incorporadas. A ambientalização das IES públicas surge então como um desafio. Algumas mudanças são necessárias tanto nas estruturas acadêmicas quanto no fazer pedagógico para que estas possam se apropriar do saber ambiental.

\section{PALAVRAS-CHAVE}

educação superior, universidades públicas; ambientalização; educação ambiental. 
FOR THE MARKET OR FOR CITIZENSHIP? ENVIRONMENTAL EDUCATION IN PUBLIC INSTITUTIONS OF HIGHER EDUCATION IN BRAZIL

\begin{abstract}
Public universities are being called upon to search for solutions to the environmental crisis. However, the different views of the environment can postpone actions that solve problems. The environmental actions undertaken in the universities are still considered sporadic and of little expression, with the predominance of a naturalist view and the belief in technology as a solution. The involvement of companies in the courses can influence the production of knowledge and also reduce college education to the role of serving the interests of the market. These can delay the overcoming of problems, since critics of the current model of exploration/production/ consumption/profit are not incorporated. The environmentalization of the public universities arises then as a challenge. Some changes are necessary such as in the academic structures and in pedagogical practices so that they can utilize environmental knowledge.
\end{abstract}

KEYWORDS

Higher education; public university; environmentalization; environmental education.

\title{
¿PARA EL MERCADO O PARA LA CIUDADANÍA? LA EDUCACIÓN AMBIENTAL EN LAS INSTITUCIONES PÚBLICAS DE EDUCACIÓN SUPERIOR EN BRASIL
}

\section{RESUMEN}

Las instituciones de enseñanza superior (IES) están siendo llamadas a buscar soluciones para la crisis ambiental. Sin embargo, las diferentes visiones sobre el medio ambiente pueden retardar acciones que lleven a reales cambios. Las acciones ambientales realizadas dentro de las IES todavía son consideradas puntuales y poco expresivas, predominando la visión naturalista y la creencia en el tecnicismo. La inserción de las empresas en cursos ambientales puede influenciar la producción del saber y puede reducir la formación universitaria al atendimiento de los intereses del mercado retardando la superación de los problemas, ya que de esa manera no se incorporan críticas sobre el actual modelo de exploración/producción/consumo/lucro de la sociedad. La ambientalización de las IES públicas surge entonces como un desafío. Algunos cambios son necesarios tanto en las estructuras académicas como en la acción pedagógica para que éstas puedan apropiarse del saber ambiental.

PALABRAS CLAVE

educación superior; universidades públicas; ambientalización; educación ambiental. 


\section{INTRODUÇÃO}

Diante da crise ambiental em que se vive hoje, a educação ambiental vem sendo considerada cada vez mais importante para a superação dos problemas ambientais em busca de uma sociedade mais justa e sustentável. A educação ambiental aqui é entendida como uma educação política, que reivindica e prepara os cidadãos para exigirem justiça social e ética nas relações socioambientais (Reigota, 1994), bem como é uma práxis social que contribui no processo de construção de uma sociedade orientada por novos paradigmas, distintos dos atuais, nos quais a sustentabilidade da vida é primordial (Loureiro, 2002).

Para tanto, as instituições de ensino superior (IES), por serem espaços de reflexão, geração de conhecimentos, preparo de estudantes para as futuras práticas profissionais e desenvolvimento de pesquisas e tecnologias, vêm sendo convidadas a assumir a iniciativa de buscar possíveis alternativas e soluções para a problemática. Como consequência, o número de cursos que levam o nome ambiental (educação ambiental, gestão ambiental, direito ambiental etc.) aumentou consideravelmente nos últimos anos dentro das universidades (Reis et al., 2005).

Entretanto, considerando o meio ambiente como um campo social (Loureiro; Barbosa; Zborowski, 2009) em disputa por diversos grupos (ativistas, cientistas, empresários, setores governamentais, instituições de ensino, organizações não governamentais etc.) relacionados, mais ou menos diretamente, com a questão ambiental (Lima, 2005), a compreensão sobre o meio ambiente pode assumir diferentes interpretações, dependendo dos contextos e/ou interesses envolvidos. As múltiplas interpretações do campo ambiental não garantem, portanto, uma convergência em suas ações (Carvalho, 2006), gerando, na verdade, discursos e práticas que têm a finalidade de atender a interesses diversos (Leff, 2001b).

Este artigo tem como objetivo apresentar um levantamento dos diversos cursos de graduação voltados para a área ambiental nas IES públicas brasileiras, bem como, com base em pesquisas bibliográficas e análises documentais, discutir a inserção das questões ambientais nessas instituições, refletindo sobre as dificuldades e os desafios a serem superados por elas na busca por soluções à crise socioambiental.

\section{QUESTÕES PROBLEMÁTICAS}

\section{AS EDUCAÇÕES AMBIENTAIS}

A educação ambiental surge como parte de uma proposta em busca de soluções aos problemas ambientais e de mudanças de paradigmas da sociedade atual. A educação, que por si só é um campo de estudo complexo, foi considerada um dos mais importantes desafios da humanidade no século XXI (UNESCO, 1999). Por conseguinte, a educação associada às questões ambientais se estabelece como um desafio ainda maior.

Uma relevante constatação na análise da relação entre educação e meio ambiente é a de que não há uma única educação ambiental, e sim múltiplas propostas baseadas em diferentes concepções de mundo, de sociedade, de meio ambiente (Lima, 1999) e de educação. Nessa linha de pensamento, Loureiro (2005) dividiu as 
concepções da educação ambiental em dois grandes grupos: um grupo denominado conservador e o outro chamado de crítico.

A educação ambiental conservadora, comportamentalista ou ainda acrítica possui uma compreensão naturalista e conservadora da crise ambiental; atribui como objetivo da educação mudanças comportamentais individuais sem considerar as relações sociais; dá pouca ênfase à problematização da realidade e aos processos históricos; foca na redução do consumo de bens naturais, sem discutir o modo de produção; tem pouco entendimento da relação homem-natureza; e dá-se de forma descontextualizada e despolitizada (idem).

Nessa linha de pensamento, Brügger (1994) explica que uma educação conservadora é uma educação-adestramento, ou seja, os ensinamentos levam à adequação dos indivíduos ao sistema vigente, conduzindo-os ao uso racional dos recursos naturais, entretanto sem gerar qualquer reflexão.

Já a educação ambiental transformadora, emancipatória ou crítica busca a autonomia e a liberdade das sociedades, redefinindo o modo de relacionamento do homem com as outras espécies e com o planeta; dá-se de forma politizada; acredita na participação social e no exercício da cidadania; preocupa-se com o diálogo entre diferentes ciências e cultura popular; possui compreensão da ligação entre produção e consumo, lucro, interesses privados e interesses públicos; e busca a transformação dos valores e práticas sociais a favor do bem-estar social, da equidade e da solidariedade (Loureiro, 2005).

Diante dessa contextualização em relação às diferentes abordagens práticas e teóricas da educação ambiental, a questão educacional, na prática, pode ser conduzida de forma libertadora ou opressora, dependendo das concepções dos grupos que dividem e disputam esse campo. Tanto a educação quanto o meio ambiente são questões essencialmente políticas, que podem vir a ser usadas para atender a visões e interesses diversificados (Lima, 1999), podendo compactuar com a visão hegemônica de mundo e seus problemas socioambientais ou levar à busca por transformações e libertação social.

A urgente transformação social de que trata a educação ambiental visa à superação das injustiças ambientais, da desigualdade social, da apropriação capitalista e funcionalista do ambiente e da própria humanidade. Brügger (1994) questiona o porquê da necessidade de uma educação ambiental, já que toda educação deveria ser ambiental. Janke e Tozoni-Reis (2008) explicam que o adjetivo ambiental, ao qualificar a educação, o faz justificadamente em razão de a educação atual não incorporar a temática ambiental de forma efetiva, uma vez que a educação tradicional atribui valores utilitários à natureza (Grün, 1994), favorecendo a difusão da visão antropocêntrica e individualista da atual sociedade. Por essa razão, neste artigo propõe-se, ao se introduzir o tema ambiental na educação, um olhar crítico sob as relações sociais e ambientais.

\section{A UNIVERSIDADE ENTRE O PÚBLICO E O PRIVADO}

A universidade pública é um espaço privilegiado de resistência crítica, política e cultural (Paula, 2000), podendo ser considerada, conforme afirma Leher (2003), a 
única instituição capaz de antecipar o que pode vir a ser problema para a sociedade e denunciar conflitos provocados por interesses particulares.

Para isso, entretanto, a universidade pública deve ser autônoma, ou seja, como esclarece Chaui (2003), capaz de autodeterminação das políticas acadêmicas, dos projetos e das metas da instituição, e autônoma na condução administrativa, financeira e patrimonial. Para Leher (2003), a autonomia desses espaços públicos de produção e socialização do conhecimento garante a liberdade de ingerências indevidas dos governos, das igrejas, das empresas e de interesses particularistas, sobretudo os econômicos.

Entretanto, nas últimas décadas, a educação sofreu grande influência do ideário neoliberal (Ahlert, 2003), que postula que os poderes públicos devem transferir ou dividir suas responsabilidades administrativas com o setor privado, como forma de estimular a competição e o aquecimento do mercado (Azevedo, 2001). Dessa maneira, a educação passou a ter um papel estratégico para o projeto neoliberal. Os governos liberais passaram a intervir no sistema educacional juntamente com as empresas privadas, direcionando a formação para atender aos objetivos unicamente do mercado, preparando pessoas para o local de trabalho, com uma visão meramente tecnológica e fragmentada. A educação também foi usada para a difusão do liberalismo como a única maneira de organização social por meio da livre iniciativa e do livre mercado, atacando o gigantismo do Estado e sua incompetência em conduzir a produção e a sociedade (Ahlert, 2003).

Assim, conforme explica Tozoni-Reis (2001), dentro do ideário neoliberal, a desobrigação do Estado enquanto financiador das atividades das universidades públicas fez com que estas fossem em busca de fontes alternativas de financiamento, colocando em risco exatamente a autonomia.

Até mesmo a intensa reformulação da política de educação superior nos últimos anos - como o Sistema Nacional de Avaliação da Educação Superior (SINAES); a Lei de Inovação Tecnológica; o Projeto de Parceria Público-Privada (PPP); o Programa Universidade para Todos (ProUni); a política de educação superior a distância, especialmente a partir da criação da Universidade Aberta do Brasil; e o Programa de Apoio a Planos de Reestruturação e Expansão das Universidades Federais (REUNI) - é considerada por diversos autores (Leher, 2004; Leher; Lopes, 2008) como reforma neoliberal, pois atende a pressupostos e exigências de organismos internacionais do capital, como o Banco Mundial, o Fundo Monetário Internacional (FMI) e a Organização Mundial do Comércio (OMC).

Nesse contexto, as universidades públicas foram invadidas por uma série de programas, editais e convênios que expressam interesses particularistas, gerando uma privatização dentro desses espaços. Essas parcerias alteram a concepção de universidade pública, uma vez que estas passam a atrelar-se às demandas externas tanto do Estado quanto do setor produtivo (Pacheco, 2012), diminuindo seu caráter de instituição da sociedade voltada para a formação humana e para a produção do conhecimento engajado na solução de problemas nacionais (Leher; Lopes, 2008).

Assim, a universidade, privada dos pressupostos estatais e com o desafio de manter-se viva com base em sua autossuficiência, encontra-se subordinada, em alguma medida, à lógica do mercado (Riojas, 2003). Essa dependência pode significar 
alto risco para a produção de conhecimentos, que passa agora a ser dirigida segundo as necessidades e o interesse do mercado, conforme explica Leher (2011, p. 162):

Os senhores do dinheiro organizam e buscam estratégias para ampliar, cada vez mais, o controle sobre a escola e a universidade, objetivando definir o que é dado a pensar para a juventude brasileira. O objetivo é a inculcação da moral, da "ética" e dos valores burgueses em seu momento neoliberal.

Como consequência, as universidades passaram a servir a uma parte específica da sociedade, ignorando a outra. Diante de tudo isso, a educação com valores éticos e de cidadania perdeu-se na valorização do "cidadão" competitivo e individualista. $\mathrm{O}$ termo "cidadania", hoje, popularizou-se e, segundo Ahlert (2003, p. 59), "tornou-se refém do discurso das elites".

Buarque (2003, p. 13) afirma que:

O modelo civilizatório excludente fez com que os profissionais formados pelas universidades passassem a servir quase que exclusivamente a um dos lados da sociedade: o lado dos incluídos nos benefícios sociais [...]. Os cursos oferecidos nas universidades pouco têm a ver com os interesses das grandes massas. Os cursos de Economia buscam maneiras de aumentar a riqueza e, em raros casos, estudam a superação da pobreza. Os cursos de Medicina estão mais interessados em não deixar que os ricos morram ou envelheçam do que em evitar a mortalidade infantil. Os arquitetos se preocupam em construir mansões e edifícios para os ricos, e quase nunca pensam em soluções para os problemas habitacionais dos pobres. Os cursos de Nutrição dão mais ênfase a emagrecer os ricos do que a engordar os pobres.

Assim, a educação vem sendo mercantilizada pelo mesmo sistema que mercantiliza a natureza, que promove a competição, incentiva a apropriação dos recursos naturais e desvaloriza a vida. Nessa linha de pensamento, trazendo essas reflexões para se pensar sobre os profissionais da área ambiental formados pelas IES públicas brasileiras, questiona-se: quantos desses profissionais que levam o diferencial do nome ambiental estão sendo preparados para garantir direitos e lucros às empresas e ao mercado? E quantos, diante de impasses e conflitos socioambientais, se posicionarão a favor das minorias, dos socialmente excluídos e dos, normalmente, injustiçados?

\section{A RESULTANTE: UMA COMPLEXA RELAÇÃO ENTRE O MEIO AMBIENTE E A UNIVERSIDADE}

A educação ambiental, no que se refere ao ensino superior, é uma área de conhecimento ainda pouco conclusiva, e, segundo Santos e Sato (2006), há a necessidade de se buscar um elo epistemológico que contribua para a inclusão dela no ensino superior.

No Brasil, a inserção do tema meio ambiente nas universidades ocorreu a partir das décadas de 1970 e 1980, quando cursos de graduação tradicionais, como 
os de engenharia, biologia, geografia, entre outros, passaram a incluir, de forma isolada e pontual, algumas disciplinas em sua grade curricular (Reis et al., 2005). Em seguida, as questões ambientais passaram a ser incorporadas por cursos de pós-graduação, por meio de doutorados e mestrados de outras áreas temáticas já constituídas, que passaram a aceitar projetos sobre temas ambientais; pela organização de novos cursos de pós-graduação lato sensu e de especializações em meio ambiente; e pela formação de programas de pós-graduação ambientais stricto sensu com ênfases diversas (Layrargues, 2003).

Contudo, foi só no final da década de 1990, provavelmente influenciados e motivados pela Rio-92, ${ }^{1}$ que houve uma explosão de cursos sequenciais, tecnológicos e de graduação no Brasil, com as mais variadas denominações (gestão ambiental, engenharia ambiental, direito ambiental etc.) (Reis et al., 2005).

Apesar da abertura e criação desses diversos cursos, para Leal Filho (1999), as ofertas, naquela época, não foram satisfatórias para garantir ao país um número suficientemente grande de profissionais habilitados para lidar com as questões relacionadas ao meio ambiente e enfrentar de forma coerente seus diversos desafios.

Ao pesquisar o site do Instituto Nacional de Estudos e Pesquisas Educacionais Anísio Teixeira (INEP), vinculado ao Ministério da Educação (MEC), é possível encontrar hoje, no Brasil, 215 cursos de graduação nas IES públicas que levam o nome ambiental, sendo os mais abundantes os denominados gestão ambiental, engenharia ambiental, saneamento ambiental e diversos outros cursos de engenharia com especificações diversas, tais como engenharia ambiental e sanitária e engenharia agrícola e ambiental, entre outros (Quadro 1).

Entretanto, chama-se a atenção para quatro cursos voltados para a área ambiental que, apesar de serem minorias, parecem que foram criados levando em consideração a demanda e realidade da região onde estão inseridos. É o caso do curso de gestão territorial indígena e meio ambiente em Roraima, onde $45 \%$ da área do estado são compostas por terras indígenas (IBGE, 2009); o curso de engenharia de minas e meio ambiente, oferecido em parceria com a empresa de mineração Vale, no estado do Pará, onde a atividade vem crescendo nos últimos anos, especialmente na cidade de Marabá, onde se encontra a oferta do curso; o curso de geofísica marinha e ambiental no estado do Rio de Janeiro, onde a indústria petroquímica gera muitos empregos; e o curso de turismo e meio ambiente na cidade de Bonito, no estado de Mato Grosso do Sul, região que cada vez mais recebe turistas em busca de contato com os atrativos naturais do local.

1 Conferência das Nações Unidas para o Meio Ambiente e o Desenvolvimento, ou Rio-92, realizada em 1992 na cidade do Rio de Janeiro. Desse encontro internacional resultou uma série de documentos importantes, como a Agenda 21, a Declaração de Princípios sobre as Florestas, a Convenção sobre Mudança do Clima e a Convenção sobre a Diversidade Biológica. 


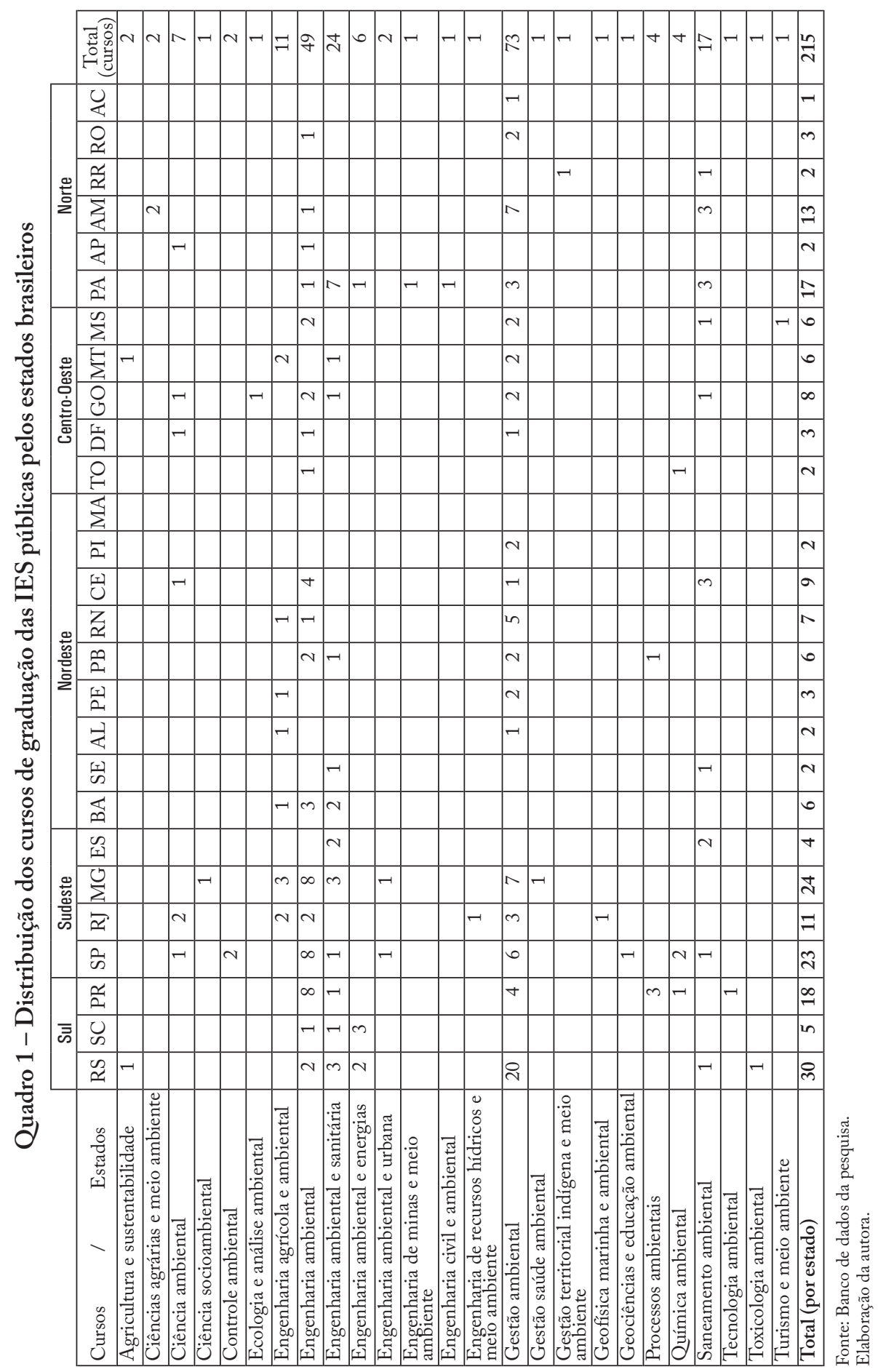


Quadro 2 - Número de cursos e vagas disponíveis por estado e região

\begin{tabular}{|c|c|c|c|c|c|}
\hline & & Número de cursos & Total & Número de vagas & Total \\
\hline \multirow{3}{*}{ Sul } & RS & 30 & \multirow{3}{*}{53} & 1.804 & \multirow{3}{*}{3.304} \\
\hline & $\mathrm{SC}$ & 5 & & 320 & \\
\hline & PR & 18 & & 1.180 & \\
\hline \multirow{4}{*}{ Sudeste } & $\mathrm{SP}$ & 23 & \multirow{4}{*}{62} & 1.930 & \multirow{4}{*}{4.202} \\
\hline & RJ & 11 & & 750 & \\
\hline & MG & 24 & & 1.334 & \\
\hline & ES & 4 & & 188 & \\
\hline \multirow{9}{*}{ Nordeste } & $\mathrm{BA}$ & 6 & \multirow{9}{*}{37} & 285 & \multirow{9}{*}{3.169} \\
\hline & $\mathrm{SE}$ & 2 & & 130 & \\
\hline & $\mathrm{AL}$ & 2 & & 120 & \\
\hline & $\mathrm{PE}$ & 3 & & 410 & \\
\hline & $\mathrm{PB}$ & 6 & & 454 & \\
\hline & $\mathrm{RN}$ & 7 & & 772 & \\
\hline & $\mathrm{CE}$ & 9 & & 918 & \\
\hline & PI & 2 & & 80 & \\
\hline & MA & 0 & & 0 & \\
\hline \multirow{5}{*}{ Centro-Oeste } & TO & 2 & \multirow{5}{*}{25} & 160 & \multirow{5}{*}{1.355} \\
\hline & $\mathrm{DF}$ & 3 & & 220 & \\
\hline & $\mathrm{GO}$ & 8 & & 335 & \\
\hline & MT & 6 & & 340 & \\
\hline & MS & 6 & & 300 & \\
\hline \multirow{6}{*}{ Norte } & $\mathrm{PA}$ & 17 & \multirow{6}{*}{38} & 820 & \multirow{6}{*}{1.935} \\
\hline & $\mathrm{AP}$ & 2 & & 150 & \\
\hline & $\mathrm{AM}$ & 13 & & 670 & \\
\hline & $\mathrm{RR}$ & 2 & & 80 & \\
\hline & $\mathrm{RO}$ & 3 & & 175 & \\
\hline & $\mathrm{AC}$ & 1 & & 40 & \\
\hline
\end{tabular}

Fonte: Banco de dados da pesquisa.

Elaboração da autora.

São mais de 13 mil vagas que todos esses cursos, juntos, oferecem, tendo as regiões Sudeste e Sul, com destaque aos estados de São Paulo, Rio Grande do Sul, Minas Gerais e Paraná, as maiores ofertas de vagas. Já as regiões Centro-Oeste e Norte são as que possuem a menor disponibilidade de vagas, especialmente nos estados do Acre, Roraima, Amapá e Tocantins. Apesar de a região Nordeste oferecer números consideráveis de vagas, o estado do Maranhão não possui nenhum curso em IES públicas (Quadro 2).

É provável que a disponibilidade de vagas esteja atrelada à distribuição das IES, e, segundo o Censo da Educação Superior de 2011, realizado pelo INEP (2013), mais da metade das IES está localizada na região Sudeste, seguida das regiões Nordeste e Sul, ficando por último as regiões Centro-Oeste e Norte. Esses dados refletem uma histórica falta de investimentos, especificamente nessas duas últimas regiões, por parte do poder público, que, apesar de nos últimos anos estar 
investindo em políticas educacionais como as citadas no subitem anterior ("A universidade entre o público e o privado"), tentando dar conta das desigualdades regionais, ainda não conseguiu superar tais desigualdades.

Novicki (2004), Loureiro (2006) e Carvalho e Schmidt (2008) também demonstraram essas desigualdades regionais em relação ao número de produção acadêmica e participação de docentes e discentes das IES em eventos que tratam da temática ambiental, havendo maior participação e produção de pesquisadores e alunos da região Sudeste, seguida pela região Sul.

Considera-se aqui preocupante as regiões Norte e Centro-Oeste oferecerem poucas opções de cursos voltados para a área do meio ambiente. Sendo elas de grande extensão geográfica, abrangendo o bioma da Floresta Amazônica, com diversas terras indígenas e quilombolas, com enorme diversidade biológica e cultural, e sendo palco de inúmeros conflitos socioambientais, em especial pelo uso e apropriação do território, seria interessante que essas regiões investissem mais na formação de profissionais qualificados para atuarem de maneira mais consciente no enfrentamento das questões socioambientais.

Em relação às modalidades e às esferas administrativas responsáveis por esses cursos, a maioria é oferecida por IES federais e na modalidade presencial, tendo somente um curso disponibilizado por uma universidade municipal em São Paulo e quatro cursos oferecidos a distância. Também há um predomínio de cursos que oferecem o grau em bacharelado, apesar de os cursos tecnológicos também estarem bastante presentes. Somente dois cursos são de licenciatura (Quadro 3).

Já em relação ao ano de abertura dos cursos, a maioria foi criada após o ano de 2000, notando-se um predomínio nos anos de 2009 e 2010 (Quadro 4). Os cursos mais antigos são em sua maioria os de engenharia, com suas diversas especificidades na área ambiental, abertos na década de 1990 nas regiões Sul e Sudeste.

Apesar do grande número de cursos oferecidos pelas IES públicas brasileiras, pouco ainda é possível afirmar sobre a qualidade acadêmica da maioria desles e dos profissionais formados, principalmente porque muitos ainda são recentes, não havendo turmas egressas ou qualquer estudo de avaliação.

Segundo Leff (2001a), os programas ambientais avançaram lentamente, e sua oferta foi incipiente para conduzir a políticas de sustentabilidade e resolução de problemas socioambientais, reforçando a falta de profissionais aptos para trabalhar, elaborar e executar políticas ambientais eficazes, além de falta de interdisciplinaridade, ambientalização e incorporação do saber ambiental nos conteúdos curriculares e em pesquisas nas universidades.

Para Dias (2006), a essa altura a dimensão ambiental já deveria estar incorporada a todas as ações das IES e a todos os cursos, independentemente se estes estão voltados para a formação de profissionais da área ambiental. Entretanto, esse processo de ambientalização da universidade está longe de se consolidar como realidade, talvez porque muitos dos cursos criados, conforme afirmam Morales (2007) e Souza (2011), são abertos apenas para atender às demandas de mercado, não incorporando a questão ambiental de forma crítica e reflexiva.

De acordo com Leff (2001a), a incorporação do tema meio ambiente à educação formal limita-se em grande parte a internalizar os valores de conservação da 
natureza, e outros pesquisadores (Dias, 2006; Lima, 1999; Reigota, 1994; Souza, 2011) observam que as propostas educacionais para o meio ambiente têm, em geral, enfatizado os aspectos técnicos e biológicos das questões ambientais, em detrimento de suas dimensões políticas e éticas.

Quadro 3 - Número de cursos por modalidade, grau e esfera administrativa nas diferentes regiões

\begin{tabular}{|l|l|c|c|c|c|c|c|}
\cline { 3 - 8 } \multicolumn{2}{c|}{} & Sul & Sudeste & Nordeste & Centro-Oeste & Norte & Total \\
\hline \multirow{4}{*}{ Grau } & Tecnológico & 25 & 15 & 16 & 7 & 18 & 81 \\
\cline { 2 - 9 } & Bacharelado & 28 & 46 & 21 & 18 & 19 & 132 \\
\cline { 2 - 9 } & Licenciatura & 0 & 1 & 0 & 0 & 1 & 2 \\
\hline \multirow{3}{*}{ Modalidade } & A distância & 1 & 1 & 2 & 0 & 0 & 4 \\
\cline { 2 - 9 } & Presencial & 52 & 61 & 35 & 25 & 38 & 211 \\
\hline \multirow{3}{*}{ Esfera } & Federal & 49 & 55 & 35 & 24 & 35 & 198 \\
\cline { 2 - 9 } & Estadual & 4 & 6 & 2 & 1 & 3 & 16 \\
\cline { 2 - 8 } & Municipal & 0 & 1 & 0 & 0 & 0 & 1 \\
\hline
\end{tabular}

Fonte: Banco de dados da pesquisa.

Elaboração da autora.

Quadro 4-Número de cursos abertos ao longo dos anos

\begin{tabular}{|c|c|c|c|c|c|c|}
\hline & Sul & Sudeste & Nordeste & Centro-Oeste & Norte & Total \\
\hline Antes de 2000 & 6 & 6 & 1 & 2 & - & 15 \\
\hline 2001 & - & - & 1 & - & 3 & 4 \\
\hline 2002 & 1 & 6 & 2 & - & - & 9 \\
\hline 2003 & 1 & 7 & 3 & 1 & - & 12 \\
\hline 2004 & 5 & 3 & 4 & - & 2 & 14 \\
\hline 2005 & 2 & 3 & 2 & - & 3 & 10 \\
\hline 2006 & 2 & 2 & 6 & 2 & 1 & 13 \\
\hline 2007 & 3 & 3 & 4 & 4 & 3 & 17 \\
\hline 2008 & 3 & 2 & 2 & 1 & 2 & 10 \\
\hline 2009 & 8 & 8 & 5 & 8 & 10 & 39 \\
\hline 2010 & 14 & 12 & 3 & 2 & 7 & 38 \\
\hline 2011 & 3 & 8 & 2 & 3 & 6 & 22 \\
\hline 2012 & 5 & 2 & 2 & 1 & - & 10 \\
\hline 2013 & - & - & - & 1 & 1 & 2 \\
\hline
\end{tabular}

Fonte: Banco de dados da pesquisa.

Elaboração da autora. 
Para Lima (2005), a politização dos problemas ambientais não só é mais recente como ainda não foi incorporada às atividades ambientais. Entre outros motivos, essa politização é barrada pela dificuldade de entender problemas urbanos e sociais cotidianos relativos a saneamento, saúde, marginalização, consumo, produção, energia, transportes, entre outros temas, como questões ambientais. Essa dissociação entre o social e o ambiental também se deve ao predomínio de concepções que confundem meio ambiente com natureza e tendem a ver os problemas ambientais como problemas ecológicos desvinculados da sociedade e da cultura.

Leff (2001a) ainda salienta que as instituições educacionais enfrentam políticas econômicas que orientam o apoio à educação, à produção de conhecimentos e à formação profissional em função de seu valor no mercado, conforme também discutido no subitem "A universidade entre o público e o privado". Isso tem criado obstáculos à incorporação do saber ambiental na formação de profissionais-cidadãos que sejam capazes de compreender e resignificar os problemas socioambientais atuais. A educação ambiental fica, assim, reduzida a um processo geral de conscientização dos cidadãos e à incorporação do saber ambiental a uma ligeira capacitação sobre problemas pontuais, nos quais a complexidade ambiental permanece reduzida e fragmentada.

Diante da preocupação com essa temática, algumas pesquisas já foram realizadas para averiguar como a educação ambiental insere-se no contexto da universidade. Em 2005, um trabalho interessado em diagnosticar a educação ambiental nas universidades foi feito pela Rede Universitária de Programas de Educação Ambiental (RUPEA), mapeando a educação ambiental em 22 universidades brasileiras. A pesquisa constatou que as iniciativas existentes nessas IES deviam-se mais a iniciativas de grupos de docentes e pesquisadores que à existência de políticas institucionais e de incentivos de seus órgãos de gestão.

Tal constatação também foi verificada por Dias (2003) em um estudo de caso sobre os desdobramentos da realização de um projeto de educação ambiental que tinha como objetivo introduzir um sistema de gerenciamento de resíduos sólidos na Universidade Estadual de Feira de Santana (UEFS), na Bahia. A autora identificou que o impacto do projeto na comunidade acadêmica foi transitório, e entre as razões para seu enfraquecimento estava a falta de investimento da própria administração da universidade, que não contemplava em seu orçamento as ações básicas para o desenvolvimento de tal projeto, ficando as ações dependentes somente das iniciativas de diversos professores de diferentes departamentos.

Já em relação à formação profissional nos cursos voltados para a área ambiental, Souza, Kelecom e Araujo (2011), preocupados com a formação acadêmica dos futuros professores na Universidade Federal Fluminense (UFF), no Rio de Janeiro, mostraram em sua pesquisa que muitos cursos de licenciatura e pedagogia não discutem as questões ambientais e, muito menos, preparam seus alunos para trabalhar com a temática. Consequentemente, os discentes não obtêm o mínimo de conteúdo e técnicas imprescindíveis para a compreensão do real significado da educação ambiental e para a sua aplicabilidade no trabalho como docente. O déficit na formação desses alunos pode ser realidade em inúmeras outras IES do Brasil, diminuindo o impacto que a educação ambiental poderia ter na formação de pessoas críticas, políticas e conscientes, com vontade de mudanças na sociedade. 
Soares, Cavalcanti e Pimentel (2008) também pesquisaram como era o enfoque ambiental dado na formação dos profissionais dos diferentes cursos de graduação da Universidade Federal Rural do Rio de Janeiro (UFRRJ), sobretudo naqueles voltados para a área agrária e nas licenciaturas. Os autores constataram que a questão tem aparecido de maneira pontual, em eventos, grupos de pesquisa e/ou extensão. As análises efetuadas nas grades curriculares, ementas e em entrevistas com docentes mostraram que a inserção da questão ambiental se dá de maneira superficial, sendo confundida, na maioria das vezes, com conservacionismo, que, segundo Brügger (1994), instrumentaliza e reifica a natureza, e, por essa visão, somente o que é recurso e útil para o homem merece ser preservado.

Em relação a cursos diversos voltados para a área do meio ambiente, Souza (2011) pesquisou a inserção da temática nos cursos voltados para tal área nas IES públicas do estado do Rio de Janeiro. Os resultados mostraram que as questões ambientais apresentavam-se prioritariamente com enfoques técnicos e "biologizantes" nos cursos de engenharia (engenharia ambiental; engenharia agrícola e ambiental; engenharia de recursos hídricos e meio ambiente) e geofísica marinha e ambiental.

A pesquisadora também demonstrou que os projetos de interesse para o mercado, financiados por empresas, eram bastante abundantes nesses mesmos cursos, sendo muito comuns convênios de estágios entre os cursos e as empresas, enquanto projetos voltados para o interesse social eram praticamente inexistentes. Além disso, também foi constatado que a indústria do petróleo absorvia muitos desses profissionais, o que, em tese, tem seu lado positivo, pois demonstra que as empresas, necessitando atender às exigências e legislações ambientais, têm se preocupado em incorporar o tema meio ambiente em suas discussões e agendas. Entretanto, tendo esses cursos uma abordagem mais técnica das questões e com o foco na minimização dos problemas, tais profissionais, nesse caso, estão atuando nos setores de meio ambiente dessas empresas para garantir o mero cumprimento da legislação ambiental, sem questionar o modelo de produção e exploração vigente, o que atende às demandas daquelas empresas que não pretendem ou querem mudar sua forma de produção/recurso/lucro/impacto na sociedade. Percebe-se então uma relação íntima e conveniente entre as empresas e os cursos técnicos e acríticos.

Apesar de o estado do Rio de Janeiro ter sido palco de dois grandes encontros de referência mundial sobre a discussão das questões ambientais, a Rio-92 e Rio+20, ${ }^{2}$ percebe-se que suas universidades públicas não conseguiram ainda incorporar e priorizar as discussões sociais associadas ao meio ambiente em seu interior, bem como apresentam dificuldades de colocar em prática o grande desafio de dialogar com a sociedade e com outros saberes e culturas na busca por soluções socioambientais. Acredita-se que tais constatações também devem ocorrer em outras universidades de outras regiões do país com forte influência da indústria do petróleo ou outras atividades de grande impacto ambiental, tal como a mineração. Já em regiões onde a exploração industrial dos recursos naturais não tenha grande importância eco-

2 Conferência das Nações Unidas sobre o Desenvolvimento Sustentável, ou Rio+20, realizada em junho de 2012, vinte anos após a Rio-92, também no Rio de Janeiro. 
nômica, talvez as universidades tenham maior autonomia para trabalhar de forma mais crítica sobre a temática. Entretanto, tais reflexões ainda precisam ser mais bem pesquisadas e aprofundadas.

Seguindo nessa discussão, Barbieri (2004) trabalhou a inserção da educação ambiental em cursos de graduação em administração e gestão e verificou que a educação ambiental nesses cursos possuía uma abordagem reducionista e antropocêntrica, sendo feita por meio de disciplinas isoladas, palestras e ou atividades em dias comemorativos, como o Dia do Meio Ambiente. O autor avaliou que os cursos voltados para a área de gestão e administração, cujos profissionais formados quase sempre trabalhavam em empresas, são os que mais necessitam incluir a educação ambiental na formação profissional, uma vez que parte dos problemas socioambientais decorre também das empresas que utilizam indiscriminadamente os recursos naturais para produzir bens e serviços, gerando diversos resíduos direta ou indiretamente, além de impactos significativos sobre o ambiente físico, biológico e social.

Já em relação à problemática do mercado influenciando a produção do conhecimento dentro das IES públicas, Acselrad, Mello e Bezerra (2009) explicam que as empresas e os governos tendem a defender ações que podem ser chamadas de "modernização ecológica", destinadas essencialmente a promover ganhos de eficiência e a ativar mercados. Trata-se de agir exclusivamente dentro da lógica econômica, atribuindo ao setor financeiro a capacidade institucional de resolver a degradação ambiental, "economizando" o meio ambiente e abrindo mercados para novas tecnologias ditas limpas e verdes. É provável que seja por essa razão que a maior quantidade de cursos abertos nas IES é de gestão ambiental e de engenharias, em suas diversas modalidades ambientais, uma vez que estes são cursos com conhecimentos mais técnicos e atendem, então, às necessidades do mercado que se volta agora para explorar a economia "verde".

Assim, a pesquisa científica orientada para o sistema econômico vigente e a formação de profissionais para a demanda do mercado e do aparelho produtivo instalado desestimulam a produção de conhecimentos e capacidades para construir uma nova racionalidade ambiental (Leff, 2001b). Brügger (1994) faz uma crítica a esse respeito afirmando que as elites econômicas, formadas pelas IES, serão bem treinadas para fornecer soluções técnicas e, logo, "eficientes" para os graves problemas ambientais, que muitas vezes são políticos e sociais. Tais elites aprenderão a confundir desde cedo meio ambiente com natureza; problemas ambientais com poluição e pobreza; e desenvolvimento sustentável com preservação de potenciais produtivos dos ecossistemas.

Chama-se a atenção para a identificação de um curso de graduação da Universidade Federal de Minas Gerais (UFMG) que percebe que as questões ambientais estão obrigatoriamente atreladas às questões sociais, e por isso o curso leva o nome de ciências socioambientais, deixando claro seu posicionamento crítico e político nesse campo em disputa. Outros cursos de ciência ambiental também parecem ter grande potencial para desenvolver a reflexão e a formação crítica de seus alunos, conforme mostra Souza (2011) em sua pesquisa, na qual analisou a temática ambiental no curso de ciências ambientais da Universidade Federal do Estado do Rio de Janeiro (UNIRIO). O reconhecimento por parte do coordenador do curso de que o trabalho com as questões ambientais é complexo e necessita estar em constante avaliação foi 
considerado positivo, pela autora, para a construção de um saber ambiental crítico, para a melhoria da qualidade do curso e para a melhor formação dos profissionais que atuarão nessa área.

Atenta-se então para a importância da capacitação e do preparo dos profissionais que trabalham com as questões ambientais, uma vez que, conforme afirma Lima (2005), tendemos a assumir atitudes e a orientar nossas ações de acordo com as construções sociais/representações que nos estão disponíveis e, entre essas, aquelas que julgamos mais consistentes. Assim, se os problemas ambientais são entendidos como questões técnicas ou políticas, naturais ou sociais, públicas ou privadas, individuais ou coletivas, essa será a direção que se adotará nas decisões e nos comportamentos sobre o assunto, e com isso corre-se o risco de se ter profissionais que realizam apenas trabalhos que minimizam os problemas em questão, mas que, consequentemente, mantêm o ideário de práticas consumistas e degenerativas do atual modelo vigente.

Já em relação à aplicação das tecnologias e conhecimentos sobre o meio ambiente na própria infraestrutura e modelo das universidades, Chao (2005) realizou uma análise na Universidade Federal do Rio Grande do Norte (UFRN). Os resultados demonstraram a dificuldade da instituição de pôr em prática o próprio conhecimento produzido, uma vez que se constatou que uma diversidade de resíduos sólidos e efluentes químicos eram gerados e descartados sem qualquer tratamento especial. Também foi constatado que o desmatamento era um problema inerente à própria implantação da universidade, que, tendo sido feita de forma inadequada e sem planejamento, era um dos principais causadores de uma série de incômodos citados pela comunidade universitária, juntamente com a escolha inadequada da planta dos prédios, que resultou em um consumo exagerado de energia elétrica, em desperdício de água potável e riscos de impacto ao lençol freático pela inadequação das instalações sanitárias.

Acredita-se que essa também seja a mesma realidade da maioria das universidades públicas do país, uma vez que muitas foram construídas em épocas anteriores às preocupações ambientais, e, mesmo para aquelas mais recentes, o planejamento ambiental e a construção de prédios e estruturas com base em modelos de sustentabilidade são ainda pouco difundidos e valorizados, além de caros no Brasil.

Diante do apresentado, fica evidente que as ações ambientais empreendidas dentro das IES ainda são bastante pontuais, mobilizam poucas pessoas e estão pouco presentes no cotidiano da comunidade acadêmica. Assim, a ambientalização das instituições não acontece, e as ações concretas de mudanças na sociedade são lentas e insuficientes diante da crise ambiental.

As justificativas apontadas para a demora e a dificuldade de se incorporar a dimensão ambiental dentro das IES podem ser resumidas pelo estudo da RUPEA (2005): ausência de recursos financeiros, infraestrutura, políticas públicas e institucionais; poucas pesquisas sobre a temática, falta de sistematização e difusão de experiências em educação ambiental; poucos profissionais aptos para a prática da educação ambiental; e a dificuldade de diálogo entre profissionais de diferentes áreas de conhecimento devido à estrutura, à departamentalização e à rigidez do meio acadêmico. 
Já Thomaz (2006) enfatiza que a grande dificuldade de se aplicar a educação ambiental crítica dentro das IES está no fato de que a grande maioria dos professores e gestores obteve sua formação segundo experiências unicamente disciplinares. Muitas vezes esses profissionais, competentes em suas especializações, estão tão inseridos no pensamento cartesiano, reducionista e fragmentado, que não conseguem nem contextualizar seus saberes com a realidade que os cerca. A interarticulação de seus conhecimentos com outros conhecimentos e ciência torna-se, então, algo impensável.

Bursztyn (2001) aprofunda a questão mostrando, ainda, que a dificuldade de valorização da educação ambiental vai além das IES, uma vez que toda a estrutura de fomento, de avaliação, de reconhecimento e de validação das atividades de desenvolvimento científico e tecnológico no meio acadêmico está orientada para os cortes das áreas do conhecimento e suas respectivas disciplinas. Essa orientação é contrária às recomendações dos Parâmetros Curriculares Nacionais (PCN), que indicam o meio ambiente como tema transversal, e à Política Nacional de Educação Ambiental (PNEA), que recomenda que a educação ambiental seja trabalhada de forma interdisciplinar (Brasil, 1999). Assim, observam-se conflitos entre as teorias e práticas dos próprios órgãos responsáveis por formular as recomendações e divulgar os conhecimentos sobre a educação ambiental.

Toledo (2000) explica que existem duas formas divergentes de pensar na missão de educar, produzir conhecimentos e incorporar as questões ambientas nas IES: a primeira opção consiste na hiperespecialização voltada à divisão e solução dos sintomas da industrialização, que não contempla as causas profundas dos problemas socioambientais e tende a retroalimentar a lógica de sua produção. Já a segunda opção implica o desenvolvimento de perspectivas teóricas que questionam as causas profundas dos problemas socioambientais, ao mesmo tempo em que orientam a construção de um novo modelo de civilização, ou seja, que buscam alternativas de pensar o mundo, a relação entre as pessoas e entre elas e o ambiente. Esta última é a que se espera das universidades diante da emergência das questões socioambientais.

Para garantir uma educação libertadora e emancipatória, e não apenas a adaptação do indivíduo à sociedade constituída, não se pode cair no erro de educar apenas para o trabalho, pois isso significa que a cidadania se reduziria ao trabalho (Ahlert,2003). Por essa razão, deve-se estar atento à forma com a qual as empresas inserem-se em cursos voltados para a temática ambiental, pois, conforme explicam Cunha e Leite (1996), quem tem o domínio da forma de transmissão exerce o controle e possui o poder de distribuir o capital cultural.

Por essa razão, as IES precisam debater sobre sua própria função social, compreendendo a necessidade de encontrar um novo equilíbrio entre a formação técnica/profissional e a formação humanista/cultural, o que implica ampliar as ações acadêmicas para além da prestação de serviços ao mercado (Goergen, 1998). Assim, as IES têm o desafio de confrontar os paradigmas que marcam a era industrial na qual elas próprias desenvolveram-se, como o produtivismo, a especialização, a disciplinaridade (Bursztyn, 2001), a valorização do tecnicismo como solução de todos os problemas e a hegemonia da ciência sobre a natureza e outros saberes.

Nessa linha de pensamento, Leff (2001b) acredita que o saber ambiental deve sempre buscar romper com a perspectiva unicamente academicista, disciplinar e 
autorreferente da ciência moderna, que elege a si própria como forma única, superior e absoluta do conhecimento. O diálogo com outras culturas, outros conhecimentos, outras comunidades, outros atores faz-se necessário na construção desse saber.

Tauchen e Brandli (2006) enfatizam que as IES devem pôr em prática sistemas de gestão ambiental (SGA) em seus campi universitários como modelos e exemplos práticos de gestão sustentável para a sociedade, uma vez que as faculdades e universidades podem ser comparadas a pequenos núcleos urbanos, por estarem envolvidas em diversas atividades referentes à sua operação, por meio de laboratórios, salas de aulas, sanitários, bares, restaurantes, alojamentos, centros de conveniência, postos de saúde, canteiros de obras, estacionamentos, entre outras facilidades.

Assim, um campus, que precisa de infraestrutura básica - como redes de abastecimento de água e energia, redes de saneamento, coleta de lixo, vias de acesso etc. -, pode demonstrar na prática a viabilidade de projetos sustentáveis, internalizando a importância da sustentabilidade ambiental na comunidade acadêmica, com plena cooperação entre as diversas instâncias e órgãos institucionais, entre tomadores de decisão e funcionários, docentes e discentes (Marcomin; Silva, 2009).

A responsabilidade das IES perante a educação ambiental vai além de se criar cursos e de tornar os currículos mais "verdes". A ambientalização da universidade supera a concepção estrita de currículo e inclui a dimensão ambiental no fazer acadêmico/universitário (Thomaz, 2006), incorporando os princípios de sustentabilidade, entre eles a gestão ambiental de todas as atividades acadêmicas e administrativas.

Assim, espera-se que as IES busquem equilibrar a formação acadêmica, preparando, sim, os profissionais para o exercício profissional, mas sem esquecer que a educação e a cidadania são indissociáveis. Quanto mais o cidadão for educado, em todos os níveis, mais ele será capaz de buscar e exigir seus direitos e cumprir seus deveres (Canepa, 2004). Também se espera que os profissionais - que vão responder e buscar soluções para os problemas ambientais e que, muitas vezes, também vão tomar as decisões finais sobre essas questões - estejam sendo formados para trabalhar pelas minorias (ou maioria) esquecidas, falar pelas vozes não ouvidas e há muito tempo caladas, e lutar por direitos iguais a todos, buscando uma sociedade mais justa e sustentável. Pois, conforme ensina Leff (2001a, p. 150), “o saber ambiental faz falar as verdades silenciadas, os saberes subjugados, as vozes caladas e o real, submetidos ao poder da objetivação cientificista do mundo".

\section{CONSIDERAÇÕES FINAIS}

A ambientalização das universidades públicas tem se dado de forma lenta e pouco satisfatória. A visão predominante sobre o meio ambiente é a naturalista, acreditando-se também na resolução dos problemas por meio de soluções tecnológicas. A universidade ainda não se apropriou na prática do próprio conhecimento que produz, ficando os sistemas de gestão ambiental e os programas de educação ambiental pouco expressivos.

A profunda inserção das empresas privadas nas IES públicas e nos cursos voltados para a área ambiental, principalmente com financiamentos de projetos e pesquisas, pode ser considerada preocupante, uma vez que essa relação torna prio- 
ritária a produção de conhecimentos voltados para o mercado, afastando cada vez mais as IES do seu papel também social.

Nas pesquisas bibliográficas feitas foram encontradas poucas pesquisas que afirmam que a questão ambiental foi incorporada de forma crítica e efetiva dentro das IES. Provavelmente isso acontece porque, além de a educação e o meio ambiente serem campos em disputa, muitos cursos são novos e ainda estão sendo criados e avaliados internamente, conforme se avança e se aprofunda nessas discussões. Espera-se que em breve se possam encontrar mais pesquisas que reforcem essas práticas, podendo vir a servir de bons exemplos para outros programas e instituições que estão dispostos a trabalhar e contribuir para a construção desse complexo e completo campo reflexivo do saber que é o ambiental.

Pode-se dizer que as questões ambientais surgem como um novo desafio para as IES e para os cursos que pretendem preparar alunos/profissionais para atuarem com a temática ambiental. A educação para o meio ambiente deve permitir que os futuros profissionais possam ter conhecimentos, habilidades e valores voltados a colaborar com a compreensão dos problemas socioambientais existentes, bem como buscar soluções éticas e justas na construção de uma nova sociedade. Para isso, algumas mudanças parecem ser necessárias dentro das universidades, também para que estas possam aproximar-se das questões ambientais. Entretanto, considera-se ainda importante o desenvolvimento de mais pesquisas que tenham como foco as IES e o meio ambiente, com o intuito de avaliar as práticas atuais e subsidiar propostas e políticas futuras.

Sugerem-se algumas ações que em conjunto podem contribuir para a inserção e o fortalecimento das questões ambientais nas universidades, tais como: aplicação de tecnologias e conhecimentos sobre as questões ambientais nos campi das próprias universidades; introdução de sistema de gestão ambiental nas universidades; criação de cursos voltados para a área ambiental com participação de professores com diferentes formações e departamentos diversos, buscando um maior diálogo entre as ciências; inserção de disciplinas e/ou projetos de educação ambiental em todos os cursos de graduação; inserção dos cursos já existentes voltados para a área do meio ambiente, no lócus em que estes estão incluídos, com trabalhos e programas de estágios voltados às realidades locais das comunidades; participação de professores, pesquisadores e alunos das universidades em audiências públicas, em conselhos de unidades de conservação e conselhos municipais e/ou estaduais de meio ambiente; promoção de debates e palestras com lideranças locais e, dentro do possível, com populações tradicionais; realização de eventos que tenham como foco o diálogo entre diferentes culturas e saberes, incluindo aqueles marginalizados pela sociedade; busca por intercâmbio e troca de saberes/vivências/experiências entre os diferentes cursos ambientais; diálogo com o terceiro setor e os movimentos sociais; revisão das formas de avaliação dos cursos voltados para a área do meio ambiente pelos órgãos de qualificação e ranqueamento destes; e atenção às pesquisas e projetos com financiamento pelo setor privado quanto aos seus interesses.

Respondendo à pergunta inicial do título "Para o mercado ou para a cidadania?", nem para um, nem para o outro, mas para ambos, pois o que o saber ambiental nos ensina é que precisamos superar esse paradigma da dicotomia que 
fragmenta o conhecimento e separa o mundo em "homem ou natureza", "corpo ou mente", "conhecimento científico ou conhecimento popular", "desenvolvimento ou conservação". A educação para o meio ambiente dentro das IES precisa buscar o equilíbrio entre a qualificação profissional para o trabalho e a formação do cidadão consciente de seus direitos e deveres para com a sociedade, pois tanto o mercado precisa de profissionais cada vez mais qualificados na área ambiental como a sociedade como um todo precisa que esse profissionais sejam bem formados e que se insiram nela como cidadãos críticos em busca do bem comum e da justiça socioambiental.

\section{REFERÊNCIAS}

Acselrad, H.; Mello, C. C. A.; Bezerra, G. N. O que é justiça ambiental. Rio de Janeiro: Garamond, 2009.

Ahlert, A. A eticidade da educação: o discurso de uma práxis solidária/universal. 2. ed. Ijuí: Unijuí, 2003.

Azevedo,J.M.L.A educação como política pública.2.ed. Campinas: Autores Associados, 2001.

BARBIERI, J. C. A educação ambiental e a gestão ambiental em cursos de graduação em administração: objetivos, desafios e propostas. Revista de Administração Pública, Rio de Janeiro: EBAPE; Editora FGV, v. 38, n. 6, p. 919-946, nov./dez. 2004.

Brasil. Ministério da Educação. Parâmetros curriculares nacionais: meio ambiente. Brasília, DF: MEC; SEF, 1997.

Lei n. 9.795, de 27 de abril de 1999. Dispõe sobre a educação ambiental, institui a Política Nacional de Educação Ambiental e dá outras providências. Diário Oficial da União, Brasília, DF, 28 abr. 1999.

BRÜGGER, P. Educação ou adestramento ambiental? Florianópolis: Letras Contemporâneas, 1994.

Buarque, C. A universidade numa encruzilhada. Brasília, DF: MEC; UNESCO Brasil, 2003.

Bursztyn, M. Ciência, ética e sustentabilidade: desafios ao novo século. In: Bursztyn, M. (Org.). Ciência, ética e sustentabilidade. 2. ed. São Paulo: Cortez; Brasília, DF: UNESCO, 2001. p. 9-20.

CANEPA, C. Educação ambiental: ferramenta para a criação de uma nova consciência planetária. Revista de Direito Constitucional e Internacional, São Paulo: IBDC, v. 12, n. 48, p. 158-166, jul./set. 2004.

CArvalho, I. C. M. A questão ambiental e a emergência de um campo de ação político-pedagógica. In: Loureiro, C. F. B.; Layrargues, P. P.; Castro, R. S. (Orgs.). Sociedade e meio ambiente: a educação em debate. 4. ed. São Paulo: Editora Cortez, 2006. p. 53-66. .; Sснмidt, L. A pesquisa em educação ambiental: uma análise dos trabalhos apresentados na ANPEd, ANPPAS e EPEA de 2001 a 2006. Revista Pesquisa em Educação Ambiental, Ribeirão Preto: USP, v. 3, n. 2, jul./dez. 2008. p. 147-174. 
Chaо, C. H. N. Universidade e educação ambiental. 2005. 230p. Tese (Doutorado em Educação) - Universidade Federal do Rio Grande do Norte, Natal, 2005.

Chaui, M. A universidade pública sob nova perspectiva. Revista Brasileira de Educação, Rio de Janeiro: ANPEd; Campinas: Autores Associados, v. 24, p. 5-15, set./dez. 2003. Cunha, M. I.; Leite, D. B. C. Decisóes pedagógicas e estruturas de poder na universidade. Campinas: Papirus Editora, 1996.

DiAs, G. F. Educação e gestão ambiental. São Paulo: Gaia, 2006.

DiAs, S. M. F. Avaliação de programas de educaşão ambiental voltados para o gerenciamento dos resíduos sólidos urbanos. 2003. 326p. Tese (Doutorado em Saúde Ambiental) Universidade de São Paulo, Feira de Santana, 2003.

Goergen, P. Ciência, sociedade e universidade. Educação E̊ Sociedade, Campinas: CEDES, v. 19, n. 63, ago. 1998. p. 53-79.

Grün, M. Uma discussão sobre valores éticos em educação ambiental. Educação $\Xi$ Realidade, Porto Alegre: UFRGS, v. 19, n. 2, p. 171-195, jul./dez. 1994.

IBGE - Instituto Brasileiro de Geografia e Estatística. Uso da terra e a gestão do território no estado de Roraima. Relatório Técnico. Rio de Janeiro: IBGE, 2009.

INEP - Instituto Nacional de Estudos e Pesquisas Educacionais Anísio Teixeira. Censo da Educação Superior de 2011. Resumo Técnico. Brasília, DF: INEP, 2013.

Janke, N.; Tozoni-Reis, M.F. C. Produção coletiva de conhecimentos sobre qualidade de vida: por uma educação ambiental participativa e emancipatória. Ciência e Educação, Bauru: UNESP, v. 14, n. 1, p. 147-157, jan./abr. 2008.

Layrargues, P. P. A natureza da ideologia e a ideologia da natureza: elementos para uma sociologia da educação ambiental. 2003. 110p. Tese (Doutorado em Ciências Sociais) Universidade Estadual de Campinas, Campinas, 2003.

Leal Filho, W. Meio ambiente: um tema de valor estratégico para a universidade brasileira. Ambiente E' Sociedade, São Paulo: ANPPAS; Pinheiros: Annablume Editora, n. 5, p. 191-201, jul./dez. 1999.

LEFF, E. Saber ambiental: sustentabilidade, racionalidade, complexidades, poder. Petrópolis: Vozes, 2001a.

. Epistemologia ambiental. São Paulo: Cortez, 2001b.

Leher, R. A reforma do Estado: o privado contra o público. Revista Educação, Saúde e Trabalho, Rio de Janeiro: Fiocruz, v. 1, n. 2, p. 27-51, set. 2003.

.Para silenciar os campi. Educação \& Sociedade, Campinas: CEDES, v. 25, n. 88, p. 867-892, out. 2004.

.Desafios para uma educação além do capital. In: Jinkings, I.; Nobile, R. (Orgs.). Mészáros e os desafios do tempo histórico. São Paulo: Boitempo, 2011. p. 159-168.

.; Lopes, A. B. P. Trabalho docente, carreira, autonomia universitária e mercantilização da educação. In: Mancebo, D.; Silva Jr., J. R.; Oliveira, J. F. (Orgs.). Reformas e politicas: educação superior e pós-graduação no Brasil. Campinas: Alínea, 2008. p. 73-91. 
Lima, G. F. C. Questão ambiental e educação: contribuições para o debate. Ambiente E̋ Sociedade, São Paulo: ANPPAS; Pinheiros: Annablume Editora, n. 5, p. 135-153, jul./dez. 1999.

Formação e dinâmica do campo da educação ambiental no Brasil: emergência, identidades, desafios. 2005.207p. Tese (Doutorado em Ciências Sociais) - Universidade Estadual de Campinas, Campinas, 2005.

Loureiro, C. F. B. Educação ambiental e movimentos sociais na construção da cidadania ecológica e planetária. In: Loureiro, C. F. B.; Layrargues, P. P.; Castro, R. S. (Orgs.). Educação ambiental: repensando o espaço da cidadania. São Paulo: Cortez, 2002. p. 69-107.

Complexidade e dialética: contribuições à práxis política e emancipatória em educação ambiental. Educação Ẽ Sociedade, Campinas: CEDES, v. 26, n. 93, p. 1.473-1.494, set./dez. 2005.

- O primeiro ano do GT Educação Ambiental da Associação Nacional de Pós-Graduação e Pesquisa em Educação (ANPEd): um convite à reflexão. Educação e Cultura Contemporânea, Rio de Janeiro: UNESA, v. 3, n. 5, jan./jun. 2006. p. 39-58.

; Barbos A, G. L.; Zвorowski, M. B. Os vários “ecologismos dos pobres” e as relações de dominação no campo ambiental. In: Loureiro, C. F. B.; Layrargues, P. P.; Castro, R. S. (Orgs.). Repensar a educação ambiental: um olhar crítico. São Paulo: Cortez, 2009. p. 81-118.

Marcomin, F.E.; Silva, A. D. V. A sustentabilidade no ensino superior brasileiro: alguns elementos a partir da prática de educação ambiental na universidade. Contrapontos, Itajaí: UNIVALI, v. 9, n. 2, p. 104-117, ago. 2009.

Morales, A. G. M. O processo de formação em educação ambiental no ensino superior: trajetória dos cursos de especialização. Revista Eletrônica do Mestrado em Educação Ambiental, Rio Grande: FURG, v. 18, p. 283-302, jan./jun. 2007.

Novicki, V. Abordagens teórico-metodológicas na pesquisa discente em educação ambiental: programas de pós-graduação em educação do Rio de Janeiro (1981-2002). Educação e Cultura Contemporânea, Rio de Janeiro: UNESA, v. 1, n. 1, p. 35-60, jan./jun. 2004.

Paula, M. F. C. O processo de modernização da universidade: casos USP e UFRJ. Revista Tempo Social, São Paulo: USP, v. 12, n. 2, p. 198-202, nov. 2000.

PACHeco, M. D. Inserção da universidade pública no contexto do licenciamento ambiental: as tensões público-privado em um projeto de educação ambiental. 2012.102p. Dissertação (Mestrado em Psicossociologia de Comunidades e Ecologia Social) - Universidade Federal do Rio de Janeiro, Rio de Janeiro.

Reigota, M. O que é educação ambiental. São Paulo: Editora Brasiliense, 1994.

Reis, F. A. G.; Giordano, L. C.; Cerri, L. U. S.; Medeiros, G. A. Contextualização dos cursos superiores de meio ambiente no Brasil: engenharia ambiental, engenharia sanitária, ecologia, tecnólogos e sequenciais. Revista Engenharia Ambiental: pesquisa e tecnologia, Espírito Santo do Pinhal: UNIPINHAL, v. 2, n. 1, p. 5-34, jan./dez. 2005. Riojas, J. Complexidade ambiental na universidade. In: Leff, E. (Coord.). A complexidade ambiental. São Paulo: Cortez, 2003. 
RUPEA - Rede Universitária de Programas de Educação Ambiental para Sociedades Sustentáveis. Mapeamento da educação ambiental em instituiçôes brasileiras de educação superior: elementos para discussão sobre políticas públicas. São Carlos: RUPEA; Brasília, DF: MEC, 2005.

SAntos, J. E.; SAto, M. Universidade e ambientalismo: encontros não são despedidas. In:_______ (Orgs.). A contribuição da educação ambiental à esperança de Pandora. 3. ed. São Carlos: Rima, 2006. p. 31-50.

Soares, A. M.D.; Cavalcanti, D. K.; Pimentel, S. S. Jovens e meio ambiente: relações que se articulam no processo de formação profissional. Ciências Humanas e Sociais em Revista, Seropédica: EDUR, v. 30, n. 2, p. 1-12, jul./dez. 2008.

Souza, V. M. Uma discussão sobre a inserção do meio ambiente no curriculum dos cursos "ambientais" em universidades públicas do estado do Rio de Janeiro. 2011.222p. Dissertação (Mestrado em Ciência Ambiental) - Universidade Federal Fluminense, Niterói, 2011. .; Kelecom, A.; Araujo,J. A educação ambiental: conceitos e abordagens pelos alunos de licenciatura da Universidade Federal Fluminense. Revista Uniara, Araraquara: Centro Universitário de Araraquara, v. 14, n. 1, p. 52-67, jul. 2011.

Tauchen, J.; Brandli, L. L. A gestão ambiental em instituições de ensino superior: modelo para implementação em campus universitário. Gestão e Produção, São Carlos: UFSCAR, v. 13, n. 3, p. 503-515, set./dez. 2006.

Thomaz, C. E. Educação ambiental na formação inicial de professores. 2006. 106p. Dissertação (Mestrado em Educação) - Pontifícia Universidade Católica de Campinas, Campinas, 2006.

TolEDo, V.M. Universidad y sociedad sustentable: una propuesta para el nuevo milenio. Tópicos em Educación Ambiental, Guadalajara: Universidad de Guadalajara, v. 2, n. 5 , p. 7-20, ago. 2000.

Tozoni-Reis, M. F. C. Educação ambiental: referências teóricas no ensino superior. Interface - Comunicação, Saúde, Educação, Botucatu: UNESP,v. 5, n. 9, p.33-50, ago. 2001. UNESCO - Declaração mundial sobre educação superior no século XXI: visão e ação. In: Tendências da educação superior para o século XXI. Brasília, DF: UNESCO; CRUB, 1999.

\section{SOBRE A AUTORA}

Vanessa Marcondes de Souza é doutoranda em psicossociologia de comunidades e ecologia social pela Universidade Federal do Rio de Janeiro (UFRJ).

E-mail: vanessamarcondes@gmail.com

Recebido em novembro de 2013 Aprovado em outubro de 2014 